\title{
Corpo-sombra e alguns princípios necessários para o trabalho da atriz no Teatro de Sombras
}

Shadow-body and some necessary principles for the
work of the actress in the Shadow Theater

Fabiana Lazzari de Oliveira ${ }^{1}$ 


\section{Resumo}

Este artigo apresenta o conceito da expressão corpo-sombra e discorre sobre as valências e os princípios necessários para o trabalho da atriz no Teatro de Sombras a partir do uso das possibilidades no espaço cênico, quanto à visibilidade e à atuação, dando sequência a uma reflexão e análise dos tipos de percepção, dos principais conceitos e subdivisões (espacial, visual, temporal) interligando-os com os princípios técnicos do teatro de sombras contemporâneo, parte do resultado da minha tese de doutorado Da prática pedagógica à atuação no Teatro de Sombras: um caminho na busca do corpo-sombra.

Palavras-chaves: Teatro de Sombras; corpo-sombra; atriz; praxis

\section{Abstract}

This article presents the concept of the term shadow-body and discusses the valences and necessary principles for the work of the actress in the Shadow Theater from the use of the possibilities in the scenic space, visibility and acting, followed by a reflection and analysis of the kinds of perception, of the main concepts and subdivisions (spatial, visual, temporal) interconnecting them with the technical principles of the contemporary shadow theater, part of the result of my doctoral thesis. From pedagogical practice to acting in Shadow Theater: a path in search of the shadow-body

Keywords: Shadow Theater; shadow-body; actress; praxis 
Com as transformações do teatro de sombras nas últimas décadas, a atrizsombrista ${ }^{2}$ conseguiu romper algumas barreiras, sendo a mais evidente, dentre elas, o fato de deixar de fazer a projeção das silhuetas somente atrás do suporte de projeção e também em poder utilizar o seu próprio corpo para as projeções. $\mathrm{Na}$ contemporaneidade, a atrizsombrista pode tornar visíveis todos os movimentos feitos por ela. Inclusive, a própria presença da atriz aparente constitui-se elemento significante ${ }^{3}$, propondo jogos metafóricos na concepção dramatúrgica.

Em minhas investigações, o que acentuo é a pesquisa da atriz do teatro de sombras contemporâneo ocidental e sua atuação segundo princípios que norteiam o trabalho cênico. Nas inquietações presentes durante o estudo está em como trabalhar no espaço entre o corpo e a projeção da imagem da sombra no suporte: aquela zona espacial que não contém os raios luminosos e que na sequência deles acaba por gerar a imagem da sombra no suporte de projeção. Esse "entre" é a sombra na sua forma tridimensional que será projetada no suporte gerando uma imagem, no qual será o resultado do trabalho para que o espectador contemple, será a representação, a síntese da sombra na superfície, na sua forma bidimensional. Portanto, a sombra é mais ampla, é tridimensional e está contida neste espaço "entre" (vide foto 1 ).

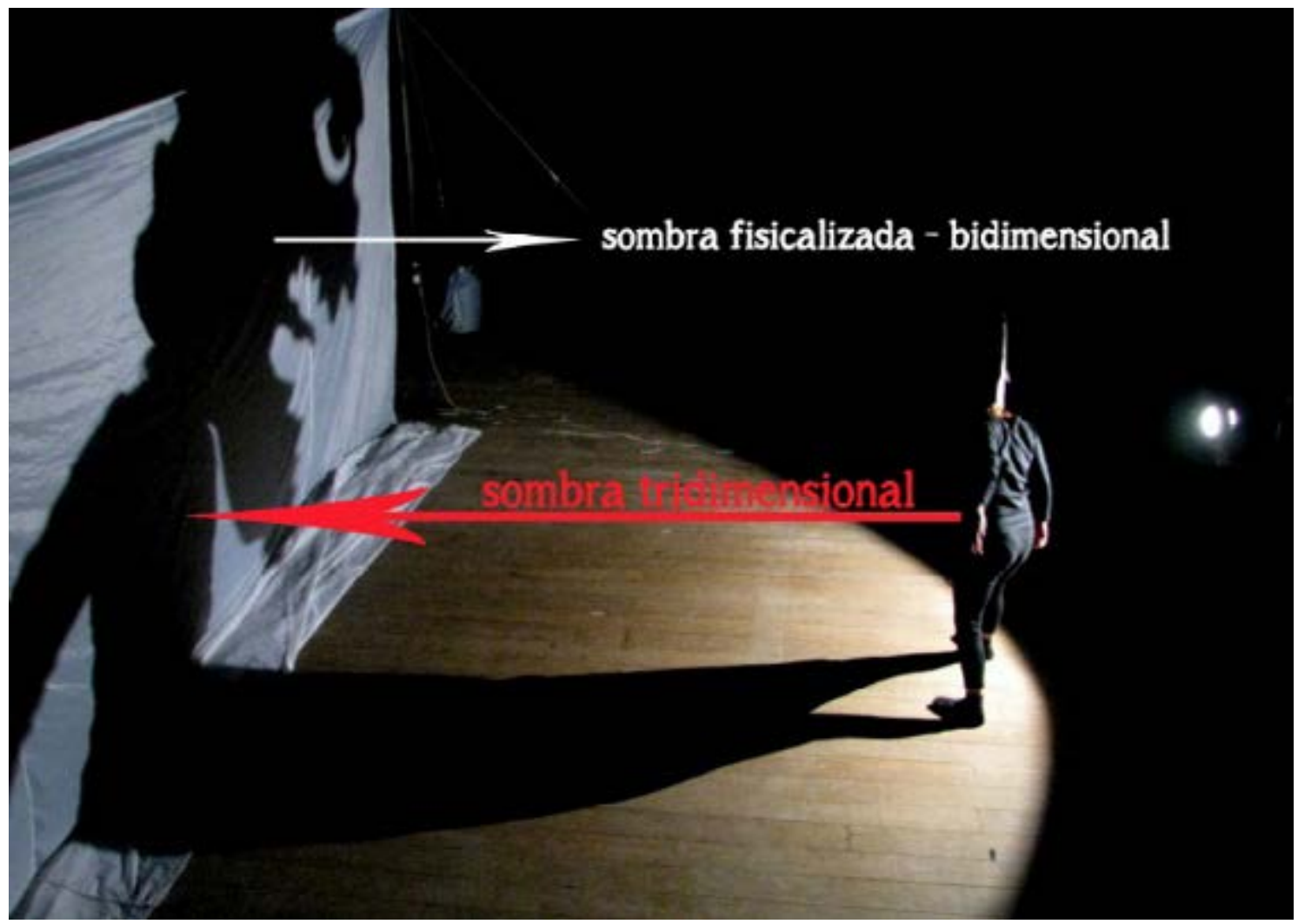

Foto 1 - Espetáculo Odisseia (2011) - Direção: Paulo Balardim Foto: Marina Medeiros

\footnotetext{
${ }^{2}$ Em todas as pesquisas e estudos que perpassei, percebi que a nomenclatura utilizada para o trabalho do/da artista que atua no teatro é a palavra "ator", generalizando a todos e a todas. Esse emprego se deve ao fato do mesmo motivo que se generaliza chamar de "homem" a todos os indivíduos da espécie humana independente do sexo. No entanto, a utilização da palavra "homem" tem sustentações na Grécia Antiga, quando os homens de fato eram tratados como o sexo padrão e superiores, as mulheres eram vistas como "um desvio" da grandiosidade masculina. Considero um hábito que reforça o caráter do sexo masculino como dominante na humanidade. Sendo contrária a este hábito, sempre que for me referir às questões que eu pesquiso e que são de minha autoria, empregarei a palavra "atriz" referindo-me tanto ao sexo feminino como ao sexo masculino, pois considero que não existem diferenças entre os gêneros quando relacionados ao trabalho da práxis e da poiésis no teatro de sombras. Nas citações e nas referências das pesquisas e estudos já existentes manterei a palavra que cada um dos autores utilizou: "ator".

${ }^{3}$ Significante é o elemento tangível, perceptível, material do signo. Um signo é um significado + significante, sendo o significado corresponde ao conteúdo e o significante à expressão, segundo o esquema Saussuriano, que consta no livro Semiologia do teatro, 2003.
} 
Com as vivências e práticas desde 2005 , ministrando oficinas, conversando com colegas atrizes e atores-sombristas e trabalhando como atriz nos espetáculos Odisseia (direção Paulo Balardim - Montagem 1 e 2 CEART/UDESC, 2011), La Tempesta (direção Fabrizio Montecchi - encenação a partir da oficina OMBRE E ALTRI FANTASMI DELLA SCENA - La scrittura scenica nel teatro d'ombre contemporaneo, Itália, 2014), Um Encanto em Nagalândia (direção Fabiana Lazzari e Tuany Fagundes - entreAberta Cia Teatral, 2015) e BRUX- (direção Alexandre Fávero, parceria Cia Teatro Lumbra e entreAberta Cia Teatral, 2017), percebi que esse trabalho da atriz no espaço está contido não somente nesta região do "entre", mas em todo espaço cênico ativo, aquele espaço utilizado pela atriz para dar vida aos personagens e ao espetáculo. A atriz, tendo percepção e consciência corporal, saberá definir as distâncias necessárias para trabalhar com a sombra e a imagem projetada da sombra e poderá ter liberdade para criar. Porém, como conseguir, da melhor forma, trabalhar com essa sombra? O que é necessário? Como tornar o corpo da atriz disponível para trabalhar com a sombra e conseguir um bom resultado artístico?

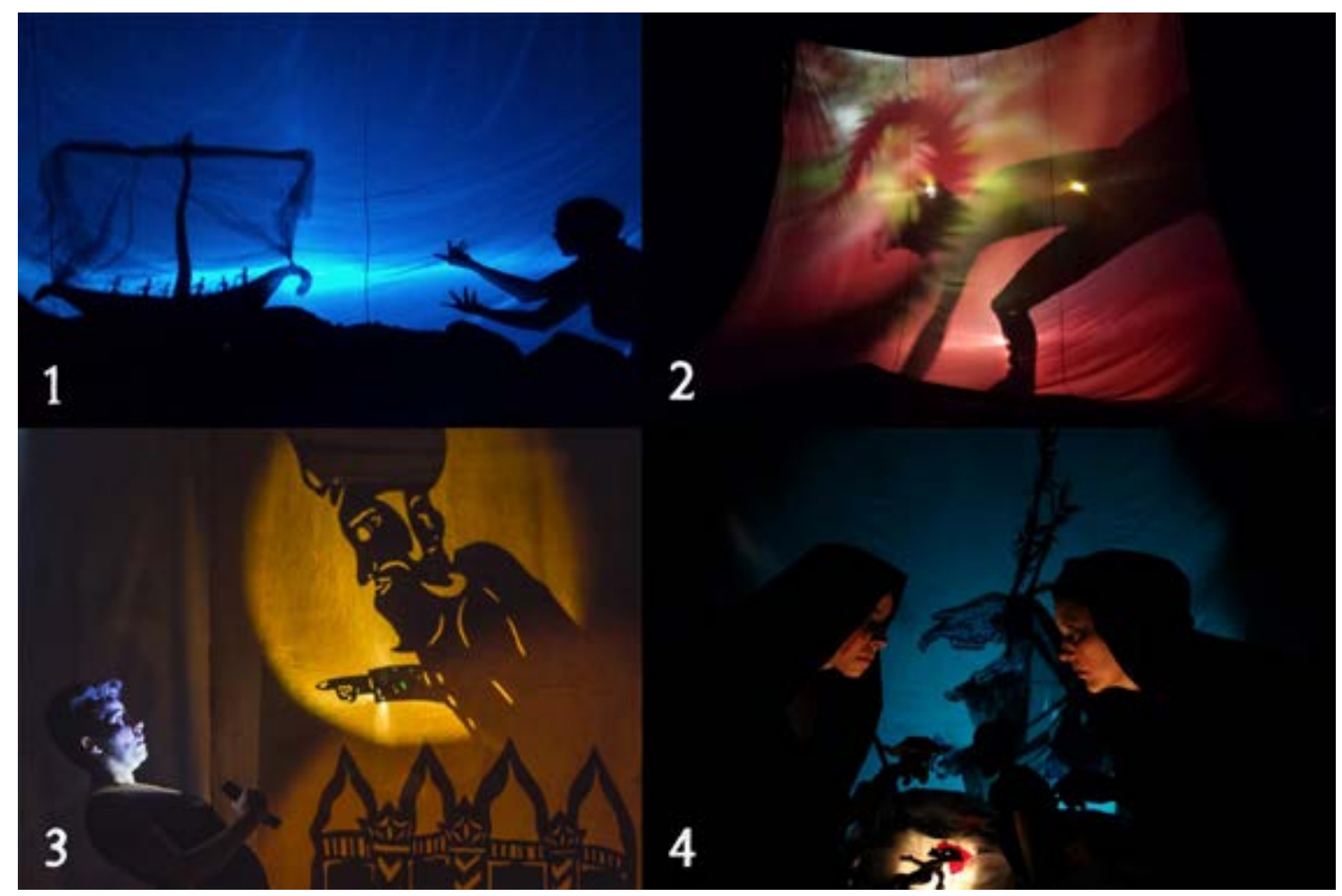

Foto 2 - Espetáculos: 1 - Odisseia (2011) - crédito: Marina Medeiros; 2 - La Tempesta (2014) - crédito: Fabiana Lazzari; 3 - Um Encanto em Nagalândia (2015) - crédito: Daniel Queiroz; 4 - BRUX- (2017) - crédito: Gisele Knutez

Surgiu então a expressão por mim utilizada: corpo-sombra. O prolongamento dos movimentos, deslocamentos e ações do corpo da atriz para a projeção da imagem da sombra são ações que necessitam ser conscientes no teatro de sombras. A atriz deve criar um estado de atenção para a representação ou a interpretação no espaço da atuação.

Para entender o corpo-sombra, é importante pensar o corpo primeiramente. Pensar o corpo é pensar nossa experiência com o mundo e suas relações de intercorporeidades. Pensar como se constrói a subjetividade - cérebro, corpo e mente 
indissociáveis. O neurocientista Antônio Damásio 4 (2003, p. 213) afirma que o corpo e o cérebro formam um organismo integrado e assim interagem completa e mutuamente por meio de projeções químicas e neurais. Isso quer dizer que sinais que vão do corpo para o cérebro e vice-versa compõem unidos as relações próprias da percepção. Para Damásio, "a percepção é tanto atuar sobre o meio ambiente como dele receber sinais" (1996, p. 256), isto quer dizer que o corpo não é algo acabado, pronto. Ele está suscetível a mudanças de estados nos momentos em que ocorre uma ação. Está sempre em processo, organizando, desorganizando e reorganizando seu universo simbólico na ação.

Damásio (2003, p. 213) explica teoricamente que a atividade cerebral está dirigida primeiramente a ajudar na regulação dos processos vitais do organismo coordenando tanto operações internas do corpo propriamente dito, como as interações entre o organismo em seu conjunto e os aspectos físicos e sociais do ambiente. Em organismos completos como o nosso as operações reguladoras do cérebro dependem da criação e manipulação de imagens mentais (ideias e pensamentos) no processo que se denomina mente; a capacidade de perceber objetos e acontecimentos externos ao organismo ou internos a ele requer imagens. As imagens relacionadas com o exterior podem ser visuais, auditivas, táteis, olfativas e gustativas.

Na área cognitiva, segundo Sandra Meyer $\operatorname{Nunes}^{5}$ (2009, p. 107) uma das questões mais debatidas é relativa ao entendimento de como algo que estava fora do corpo, passa a pertencer ao organismo. Segundo ela, as operações entre o dentro e o fora têm particularidades, pois cada vez que o corpo percebe algo de si mesmo ou do ambiente, consciente ou inconscientemente, ele se reorganiza. Nunes afirma que possuímos inúmeros processos de auto-organização, como os de "auto-afecção" que mudam constantemente nossa própria estrutura em relação ao meio interno e externo (2009, p.109). A afecção é tratada por Espinosa e relatada por Deleuze (1978): "é uma mistura de dois corpos, um corpo que se diz agir sobre o outro, e um corpo que recolhe o traço do primeiro. Toda mistura de corpos é chamada de afecção". Nesse sentido, Nunes (2009, p.109) conclui que o corpo se modifica na relação com outros corpos, uma vez afetado não será mais o mesmo, carregará a marca do contágio ocorrido.

Relacionando esse conceito da afecção com a atuação da atrizsombrista, quando ela projeta a imagem da sombra e a fisicaliza no suporte de projeção, a atrizsombrista age sobre a sombra e a sombra recolhe o traço, as características do corpo são mostradas pela imagem da sombra, o perfil mostrará um traço modificado. Este acontecimento é uma afecção. É o corpo afetando e sendo afetado. Acontecendo a afecção, os corpos sofrem alterações, as potências aumentam e diminuem. Tendo essa consciência, a atrizsombrista trabalhará seus movimentos imbricados ao da sombra, afetando e sendo afetada pela sombra no espaço tridimensional em que está inserida.

No teatro de sombras, como temos muitos elementos para trabalhar em cena, acontecem essas afecções a cada nova práxis, a cada ensaio, a cada apresentação.

\footnotetext{
${ }^{4}$ Médico neurologista, neurocientista português, professor de neurociência na Universidade do Sul da Califórnia.

5 Professora Doutora da Universidade do Estado de Santa Catarina, atriz e bailarina.
} 
As percepções se dilatam, aumentam e atingimos as micropercepções. Possuímos percepções macroscópicas que são as musculares e de movimento e com a práxis geramos sensações e afetos microscópicos. Ferracini quando fala de atuação, acentua:

É justamente nesse espaço entre a percepção macroscópica e a sensação/afeto microscópico que a atuação se territorializa. A atuação ativa faz dobrar, desdobrar e redobrar o espaço-tempo macroscópico, gerando um universo infinito de pequenas percepções ou, ainda, de micropercepções carregadas de sensações que afetam o próprio espaço-tempo recriado. A atuação opera nesse processo jorrando micropercepções, microafetações, sensações virtuais com, entre e sobre as macropercepções e macroafetações atuais e perceptivas do corpo e da cena. (Ferracini, 2013, p. 73)

Essas percepções e afetações, do macro ao micro vão aumentando à medida em que este corpo atua. E aí entra o corpo-sombra. É com ele que a atrizsombrista terá a capacidade de discernir o que deve ou não fazer em cena, como deixará o seu corpo ser afetado pelos outros corpos existentes na encenação e como vai procurar afetar os corpos que estão sendo produzidos em conjunto com a imagem da sombra projetada.

\section{O Corpo-Sombra}

O corpo-sombra é o estado de atenção multifocal da atriz na sua corporeidade e no mundo percebido produzindo autonomia e dançabilidade no espaço-tempo de atuação no teatro de sombras. A atriz deve estar em corpo-sombra para atuar no Teatro de Sombras. Mas como se adquire este estado para a atuação? O que é estado de atenção? Corporeidade? Autonomia? Dançabilidade? E que espaço-tempo de atuação é esse?

Iniciemos por entender esse estado de atenção. Robert Sternberg ${ }^{6}$ certifica que a atenção "é o meio pelo qual processamos ativamente uma quantidade limitada de informação a partir da enorme quantidade disponível através de nossos sentidos, nossas memórias armazenadas e de nossos outros processos cognitivos" (2008, p. 71). A atenção tem processos conscientes e inconscientes. Sempre temos uma riqueza de informações sensoriais, mas damos atenção apenas a uma quantidade limitada da informação sensorial que está disponível em um dado momento. Temos a possibilidade de usarmos nossos recursos mentais limitados de forma sensata, segundo o autor: "ao diminuir a atenção sobre muitos estímulos exteriores (sensações) e interiores (pensamentos e memórias), podemos focar nos estímulos que nos interessam" (Sternberg, 2008 , p. 72). E este foco dirigido aumenta a possibilidade de que respondamos rapidamente e precisamente aos estímulos que precisamos. A neurociência da atenção tem uma literatura em constante crescimento e Sternberg relata que M. Posner ${ }^{7}$ identificou dois sistemas de atenção: o sistema de atenção anterior no lobo frontal e um sistema de atenção posterior no lobo parietal (2008, p. 109). O primeiro é ativado cada vez mais durante tarefas que requerem consciência, envolvido na "atenção para a ação", o segundo é ativado durante tarefas envolvendo atenção visual-espacial. "A atenção

\footnotetext{
${ }^{6}$ Psicólogo e psicometrista estadunidense, deão de Artes e Ciências da Tufts University. Foi professor de psicologia na Yale University e presidente da American Psychological Association.

${ }^{7}$ Psicólogo estadunidense que pesquisa sobretudo o campo da atenção. Professor da Universidade de Oregon, Eugene (EUA).
} 
também envolve a atividade neural nas áreas visuais, auditivas, motoras e de associação relevantes do córtex envolvido em determinadas tarefas visuais, auditivas, motoras ou de ordem superior" (Sternberg, 2008, p. 109).

No teatro de sombras, o estado de atenção da atrizsombrista é multifocal e é acionado por meio das diversas percepções corporais, principalmente a visual, a somatossensitiva, a proprioceptiva e a cinestésica. No espetáculo $B R U X-$, ao mesmo tempo em que a atrizsombrista manipula uma fonte de luz criando um espaço-sombra para sua colega atuar com a sombra de uma silhueta/figura/boneco, ela organiza seu corpo deslizando para o lado contrário para alcançar outra silhueta/figura/boneco na sequência da cena. Nesta ação conjunta, ela está com os sentidos dilatados para todas os obstáculos ao seu redor, além de ter que atuar com a fonte de luz. Como a maioria das cenas acontecem na frente do suporte de projeção, com a atuação e manipulação visíveis ao público, além da atenção com os elementos de cena, com o seu corpo, a atriz ainda precisa manter uma postura donde deverá causar a ilusão de que tudo está sendo tranquilo. Ou ainda, enquanto uma das atrizes atua com a silhueta/figura/boneco na frente do público, a outra, no escuro, organiza o próximo cenário que será utilizado para outra cena conjunta que tem a interação das imagens das sombras corporais e silhuetas/figuras/bonecos. Mas como trabalhar com a atenção multifocal?

Para isso é importante que o corpo da atriz passe pela habituação e desabituação. A habituação, segundo Sternberg $(2008$, p. 80 ) está relacionada a acostumar-nos com um estímulo, de forma que, aos poucos, passemos a prestar cada vez menos atenção a ele. A contraparte da habituação é a desabituação, na qual a mudança de um estímulo conhecido leva-nos a começar a notá-lo novamente. A habituação dá suporte ao nosso sistema de atenção. O sistema de atenção consciente, no qual precisamos ter embasamento para o trabalho com corpo-sombra, tem três funções principais: detecção de sinais, quando identificamos o surgimento de um estímulo específico; a atenção seletiva, em que escolhemos prestar atenção em alguns estímulos e ignorar outros e a atenção dividida, na qual alocamos prudentemente nossos recursos de atenção disponíveis para coordenar nosso desempenho em mais de uma tarefa de cada vez.

No teatro de sombras, como estamos no escuro, a todo momento acionamos a atenção para a detecção de sinais, os estímulos a todo momento estão presentes e precisamos estar com essa função aflorada principalmente para que consigamos detectar erros durante o espetáculo e conseguir corrigi-los a tempo. Numa das apresentações do BRUX-, segundos antes de começarmos o espetáculo, um dos espectadores ao procurar lugar para sentar, tocou com seu pé numa das fontes luminosas que estava estrategicamente no lugar para dar início do espetáculo e a moveu. Ao mover a fonte luminosa, fez um pequeno barulho característico do arame que lhe dá suporte no chão. Naquele mesmo instante, minha percepção auditiva foi acionada. Percebi o deslocamento da fonte luminosa por meio da frequência do som, que já estava habituada a escutar. Chegando no momento de manusear a fonte luminosa que foi movida, a atenção foi dividida para conseguir detectar onde ela se encontrava. Enquanto eu desligava a outra fonte luminosa, com a outra mão e com a visão, eu procurava simultaneamente onde estava a fonte de luz que tinha sido movida. 
E o que é a corporeidade da atriz? Utilizo o conceito de corporeidade do filósofo Michel Bernard que propõe que toda corporeidade pode ser definida a partir do funcionamento intrínseco do nosso sentir. Não se trata mais de considerar uma entidade autônoma e definida que recebe/emite informações e que seria "o corpo", mas a materialização de um processo móvel e complexo, o do sentir (Bernard, 2001, p. 17-24). Essa corporeidade é mutável, e transforma-se a cada nova vivência sem abandonar as anteriores; todo contexto pelo qual passamos, as culturas, os hábitos, os costumes, vão influenciá-la, em sua maneira de ser no mundo (Merleau-Ponty, 1999). Para estar em corpo-sombra, ainda digo que, além da sua corporeidade, a atrizsombrista deve estar atenta "no mundo percebido" porque deve observar e perceber ao seu redor a tridimensionalidade em que está atuando. Isso irá modificar a sua atuação. Caso não esteja atenta ao que está fora da sua corporeidade, as imagens da sombra poderão ser diferentes e não atingirem a meta proposta na atuação, além de, se acontecer qualquer ação diferente, ao acaso, poderia causar um verdadeiro "caos" e até a impossibilidade de continuar o espetáculo.

Essa corporeidade adquirida mediante a vivência e treinamento de práxis e poiésis no teatro de sombras produz uma autonomia e uma dançabilidade no corpo da atrizsombrista. Num fluxo contínuo o corpo desliza entre os deslocamentos e ações necessárias durante a atuação. É um fluxo dinâmico e consciente. E para colocar esse corpo em fluxo contínuo, existe uma força que opera que se chama organicidade, que é gerada na relação estabelecida no espaço "entre" o conjunto de elementos da encenação. Justamente aí que a atrizsombrista atua entre a fonte de luz e o suporte de projeção, entre a zona escura e a zona iluminada, entre o suporte de projeção e o público.

A atrizsombrista age para criar afetos num espaço-tempo constantemente reelaborado, pois trabalhamos no teatro, e teatro é "aqui e agora". Sendo assim, cada apresentação é única e apesar de ser ensaiada ela estará em constante reelaboração. E nisto a atrizsombrista deve estar atenta também ao que acontece "ao acaso", "aleatoriamente", "sem intenção prévia", principalmente quando está em processo de criação, no trabalho de poiésis, pois desse "ao acaso" podem surgir novas percepções. Não podemos nos encerrar nas certezas e sim estarmos abertos ao que nos acontece fora da habituação.

Estar em corpo-sombra é estar no espaço-tempo da atuação. O teatro é uma arte que se desenvolve no espaço e no tempo, ao contrário daquelas que são espaciais, mas são imóveis como a pintura, a escultura e a arquitetura. Quem possibilita o movimento no espaço é a atrizsombrista. Seu corpo acaba tendo uma plasticidade que o coloca em relação direta ${ }^{8}$ com todos os elementos do teatro de sombras naquele tempo de atuação, do "aqui e agora" que necessita também de um ritmo determinado pelo que se quer contar e pelo tempo da imagem da sombra ou da silhueta/figura/boneco que se está atuando.

Para se chegar ao corpo-sombra é necessário um trabalho em vários níveis de percepção na práxis e na poiésis. A atriz com percepção espaço-temporal e boa

\footnotetext{
${ }^{8}$ O estudo das relações do corpo da atriz com os elementos que compõem o teatro de sombras, está contido na dissertação Alumbramentos de um corpo em sombras: o ator no Teatro Lumbra de Animação, 2011. In: https://fabianalazzari.files.wordpress.com/2011/12/alumbramentos-de-um-corpo-em-sombras-o-ator-da-companhia-teatro-lumbra-de-animac3a7c3a3o.pdf
} 
consciência corporal saberá definir as distâncias necessárias para trabalhar com a imagem da sombra projetada e poderá ter liberdade para criar. Ela deverá "ser na ação", isto é, ação e impulso acontecerem no mesmo instante. Situar ativamente o corpo-sombra em estado de consciência.

Para refletir sobre a relação da atriz com o corpo-sombra é preciso entender um pouco mais o que seria tal consciência. A consciência, segundo Sternberg, inclui "o sentimento de percepção consciente e o conteúdo da consciência, parte do qual pode estar sob o foco da atenção" (2008, p. 72). Ele ainda diz que consciência e atenção formam dois conjuntos sobrepostos.

O filósofo português José Gil, em seu artigo Abrir o Corpo, repensa alguns fundamentos ontológicos da dança e nos diz que a consciência está sempre em imbricação com o corpo:

É preciso definir a consciência do corpo não à maneira da fenomenologia (mesmo
de uma fenomenologia do corpo como a de Merleau-Ponty), não como o que
visa o sentido do objeto na percepção, por exemplo, mas como uma instância de
recepção de forças do mundo graças ao corpo; e, assim, uma instância de devir as
formas, as intensidades e o sentido do mundo.
A impregnação da consciência pelos movimentos do corpo é própria da natureza
da consciência: a sua descrição clássica como "tomada de consciência" do objeto
diferenciando-o do sujeito implica, curiosamente, essa mesma impregnação.
Não haveria tomada de consciência se esta não desposasse, de uma maneira ou
de outra, o objeto em questão. Ora "desposar" vale como metáfora que recobre
processos precisos de cognição e contágio, entre os quais a captação das formas
e das forças que animam o objeto. (Gil, 2004, p. 14).

Gil explica que para a consciência captar as características do objeto deve fazê-las suas. Ocorre uma impregnação da consciência pelo corpo e pelas forças do objeto: "o corpo inicia um devir-objeto significa, em termos deleuzianos, que se cria uma zona de indiscernibilidade entre o corpo e o objeto que faz com que o corpo transfira certos dos seus traços para o objeto, e reciprocamente, que certas propriedades do objeto se transmitam ao corpo" (2004, p. 15). Desse modo, é preciso aprender a tornar-se o objeto em questão:

Numa imagem simples e simplificadora diríamos que num estado de grande intensidade de criação artística, por exemplo, quando a consciência se deixa invadir pelos movimentos do corpo, os dois elementos convergem, transformando-se, para o espaço único em que a osmose se produzirá: é no mesmo processo de atualização do movimento virtual em movimento do corpo no espaço e em movimento de pensamento que ocorre a imbricação da consciência pelo corpo. (Gil, 2004, p. 16)

Enfim, "não há consciência sem consciência do corpo. Não há consciência sem que os movimentos corporais intervenham nos movimentos de consciência" (Gil, 2004, p. 17).

E quanto à percepção espacial, M. D. Vernon, psicólogo e autor do livro Percepção e Experiência (1974), afirma que:

$\mathrm{O}$ adulto percebe o ambiente como um todo espacial contínuo, do próximo ao distante, e esse todo inclui as partes do lado e de trás não imediatamente visíveis, 
bem como as partes vistas no momento. No entanto, há muita diversidade de informação nos esquemas em que se baseia a percepção do esquema espacial total e na reação a este. Muitos processos diferentes podem atuar na percepção e avaliação de seus vários aspectos. As imagens diferentes dos dois olhos participam da percepção e da localização e da solidez tridimensional dos objetos próximos, juntamente com as sombras nos seus lados e as sombras que projetam. As contínuas mudanças de perspectiva em tamanho, brilho e textura da superfície - que Gibson (1950a) denominou de "gradientes" - são os principais aspectos que contribuem para a percepção do "chão" em que os objetos estão localizados: no entanto, também permitem que se faça a localização de tais objetos e, por isso, permitem julgamentos quanto à distância. (Vernon, 1974, p. 136)

A atriz pode escolher aspectos do ambiente (do espaço cênico) que lhe darão informações claras e precisas para seus deslocamentos na atuação da sombra projetada. A atrizsombrista deve ser capaz de, imaginando a recepção da imagem/sombra pelo público, escolher os movimentos e orientá-los de forma desenhada, limpa, tornando-os compreensíveis em toda a sua extensão. Por isso, experiências com o corpo são primordiais à atrizsombrista, que deve conhecer o espaço do corpo com todas as variáveis citadas acima, pois no teatro de sombras há um prolongamento (invisível) de suas ações por meio do qual o espectador poderá fruir a obra.

É importante salientar que no teatro de sombras a atrizsombrista é também espectadora, porque é fundamental que ela observe as sombras que se projetam no suporte de projeção escolhido para dar anima a elas. Isso torna o teatro de sombras particularmente complexo, pois "o ator é sujeito e objeto do seu ato de criação" (Beltrame, 2005, p. 52). Beltrame analisa o ator-animador no teatro de sombras e afirma que ele precisa prolongar ainda mais seu fluxo de energia para transmiti-lo à sombra, para se tornar a sombra:

$\mathrm{Na}$ atuação o olhar do intérprete deve controlar a imagem projetada na tela, a sombra; e o movimento da silhueta nem sempre condiz com o movimento da sombra/ imagem. [...] $\mathrm{O}$ ator-animador representa a personagem (está nele), seleciona ações e movimentos para o objeto que anima (fora dele) e projeta ao público as imagens das ações e movimentos da personagem que estão fora do objeto. Ou seja, o que o ator animador mostra não só está fora dele como também está fora do objeto que manipula. A personagem é a sombra do objeto. (Beltrame, 2005, p. 54)

E ainda, o personagem pode ser a sombra do corpo da atriz ou parte dele. Além de ter a consciência do corpo se movimentando, a atriz precisa ter a percepção de como a projeção de sua sombra se movimenta para atuar com ela de acordo com o posicionamento da fonte de luz, que pode estar fixa ou em movimento. $O$ corpo-sombra é o estado consciente criativo da atriz em cena, pelo qual atua mesmo com seu corpo oculto para o público, manipulando silhuetas fora da zona iluminada para projeção da sombra. Vejamos agora a melhor forma de se trabalhar com essa sombra. O que é necessário?

Assim como o bailarino que segrega, cria o espaço com o seu movimento, e não somente se desloca no espaço, o ator no teatro de sombras também transforma o espaço da cena fazendo-se o corpo-sombra um só.

Um dos espaços do corpo que a atriz trabalha no teatro de sombras é o espaço prolongado até a projeção da imagem da sombra, até o espaço escuro (massa cin- 
zenta, imagem da sombra) ou colorido, formado no suporte. Esse espaço é como se fosse um invólucro que suporta o movimento da atriz para criação da imagem da sombra. Correlaciono com duas funções que Gil (2009, p. 49) atribui ao espaço do corpo: "aumentar a fluência do movimento, criando um meio próprio, com menor viscosidade possível e tornar possível a posição de corpos virtuais que multiplicam o ponto de vista do bailarino".

O trabalho de uma atriz no teatro de sombras possui muitas características similares ao trabalho de um bailarino. Gil mostra que o movimento dançado se aprende: "é necessário adaptar o corpo ao ritmo e aos imperativos da dança" (2009, p. 49). No teatro de sombras o corpo da atriz também precisa adaptar-se ao ritmo, às potencialidades e às escolhas de manipulação das fontes de luz e dos suportes de projeção. Se a fonte de luz é fixa, a atriz terá uma disponibilidade de ritmo diferenciada de quando as fontes de luzes são móveis e manipuladas por outra atriz, além também de estar consciente de que tipo de movimento se quer dar à imagem que vai projetar com o corpo e que ritmo a mesma tem. Portanto, esse corpo-sombra é considerado aqui o corpo consciente do corpo que produz a sombra. A aquisição dessa consciência é um processo similar à aprendizagem técnica da dança, citado por Gil:

\begin{abstract}
Diante do espelho, o aluno aprende a fazer corresponder certa posição dos membros a certa tensão cinestésica, construindo assim um mapa interior dos movimentos que lhe permitirá evoluir de modo preciso sem ter já de recorrer a uma imagem exterior do seu corpo. [...] o opor tem de se abrir ao espaço, tem de se tornar de certo modo espaço; e o espaço exterior tem de adquirir uma textura semelhante à do corpo afim de que os gestos fluam tão facilmente como o movimento se propaga através dos músculos. [...] o corpo move-se nele sem enfrentar os obstáculos do espaço objetivo estranho, com os seus objetos, a sua densidade, as suas orientações já fixadas, os seus pontos de referência próprios. No espaço do corpo, este cria os seus referentes aos quais as direções exteriores devem submeter-se (assim o icosaedro de Von Laban comporta também vetores). (2009, p. 50)
\end{abstract}

Creio que é isso que acontece com o corpo consciente atuante no teatro de sombras, porém, nesse temos um diferencial da dança que é a projeção dos movimentos no suporte de atuação da sombra. Eles aparecem na imagem da sombra, do corpo ou do objeto, projetada. Existe uma delimitação de espaço para a atuação da sombra a ser vista, tanto pela atriz como pelo espectador e isso é uma premissa da consciência corporal da atrizsombrista. $O$ estado de atenção permanente se revela como fator essencial e indispensável. Porém, percebo em cursos ministrados e acompanhamento das aulas de teatro de sombras na Universidade que seguidas vezes, a atriz iniciante na atuação com teatro de sombras pode ter uma aptidão física boa (isto é, tem condicionamento cardiorrespiratório, força e resistência muscular, equilíbrio e alongamento satisfatórios), mas não consegue tão facilmente ter o tempo e o ritmo para trabalhar com a atuação da sombra. Por que isso acontece? O que se precisa para que essa atriz adquira tais potencialidades?

As relações da atriz com seu corpo e com todos os elementos do teatro de sombras dependem da percepção em suas diversas vertentes, inclusive no espaço-sombra: espaço "entre" a fonte de luz e o suporte para projetar a imagem da sombra. Quando se reflexiona sobre a sombra e quando a sombra é utilizada intencionalmente 
pensando-se o jogo cênico, a atrizsombrista precisa conscientizar-se da presença de seu corpo, utilizar-se da consciência do corpo-sombra. Dessa forma, trabalhará melhor sua ausência ou presença no espaço de criação.

O corpo é moldado de acordo com as necessidades, porém todos nós temos um passado que está intrínseco em nosso corpo e que é um espaço a ser descoberto. 0 corpo e o espaço no teatro de sombras estarão sempre em transformação de acordo com as escolhas poéticas dentro da linguagem, isto é, de acordo com o material utilizado, com a forma na qual a atriz se utilizará da manipulação das silhuetas/figuras/ objetos/bonecos/corpos e da atuação com a sombra.

\section{Valências e princípios para o trabalho da atriz no Teatro de Sombras}

Destarte, a partir das relações de cada elemento do teatro de sombras todas elas intrinsicamente ligadas, e do que falamos acima sobre o corpo-sombra podemos discorrer sobre algumas valências e princípios necessários para o trabalho da atriz no teatro de sombras.

Primeiramente, resumo algumas possibilidades da atrizsombrista no espaço cênico. Quanto à visibilidade: ela pode estar oculta ou aparente (à vista) do público. A atriz-sombrista oculta está atrás do suporte de projeção e fora do espaço da direção dos feixes luminosos (foto 03); já a atrizsombrista aparente estará num espaço visível ao público, pode estar atrás ou à frente do suporte de projeção, assim como dentro ou fora do espaço de direção dos feixes luminosos (foto 04). Nesta segunda situação, surgem novas condições e relações na cena, pois mesmo a atrizsombrista estando neutra e com roupas escuras, a sua presença é evidente para o público, qualquer movimento que faça, por menor que seja, é visto pelo público e isto traz outras possibilidades para a poética do espetáculo como, por exemplo, interpretar um personagem ou ser uma narradora da história, trazendo também mais desafios.

Quanto à atuação: a atriz pode atuar somente com a silhueta/figura/boneco/ objeto (foto 03), atuar com a sombra de seu corpo e a sombra da silhueta/figura/ boneco/objeto, atuar com partes do seu corpo para completar a sombra da silhueta/ figura/boneco/objeto, ou atuar com a sombra do próprio corpo e com a sombra do corpo da outra atriz (foto 05). E ainda, dentro dessas possibilidades para atuação, a mesma pode ser executada com fontes de luz fixas ou com fontes de luz móveis: quando as fontes luminosas forem móveis, quem as manipula é a própria atriz, necessitando ter mais destreza, atenção e habilidades motoras para coordenar os movimentos em conjunto ou separadamente. Cada uma dessas situações envolve percepções corporais diferentes e complexas. 


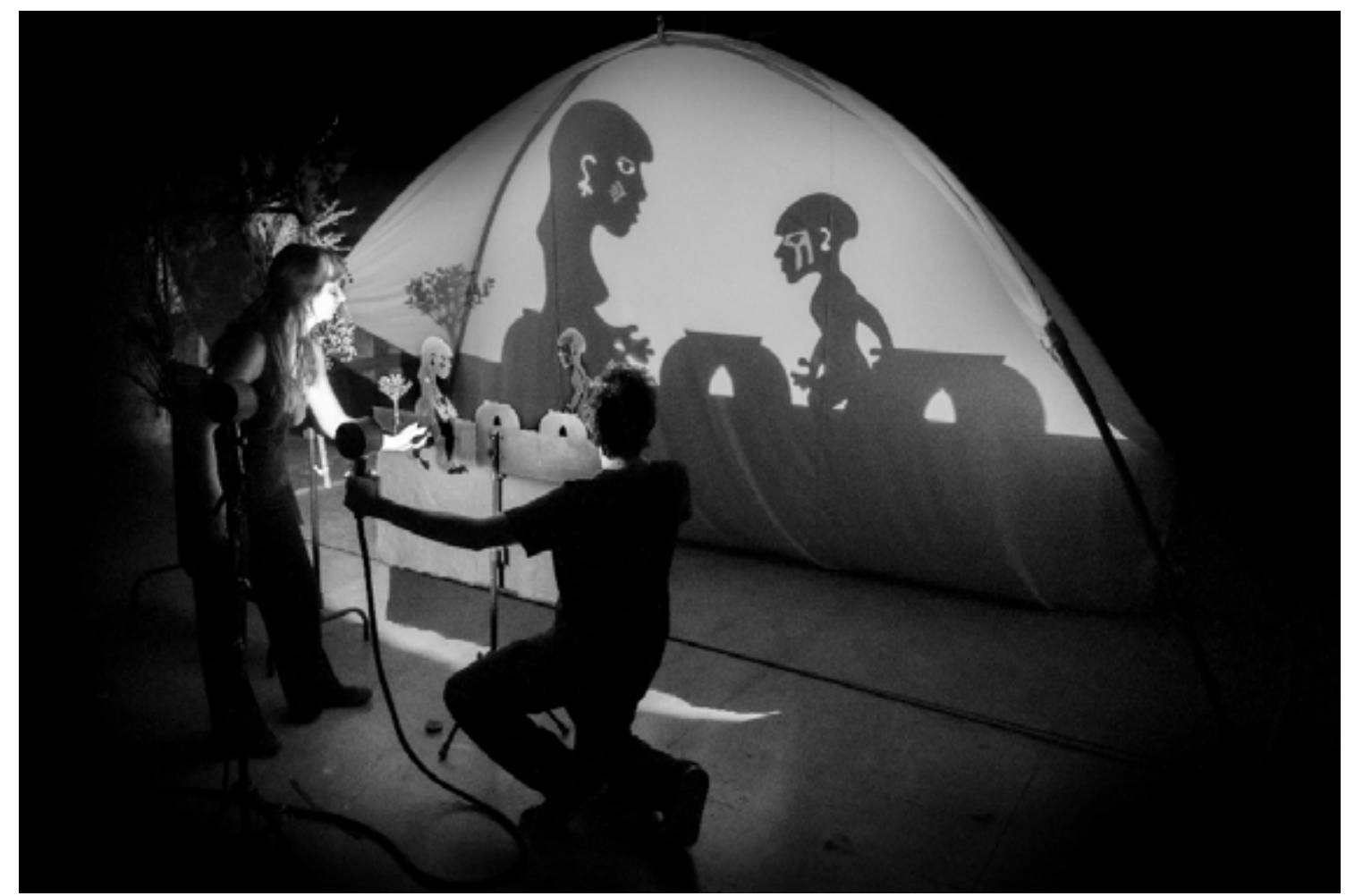

Foto 03 - Atriz e ator-sombristas ocultos no espetáculo lara, O Encanto das Águas (2014), Cia Lumiato, Brasília Direção: Alexandre Fávero - Foto: Diego Bresani.

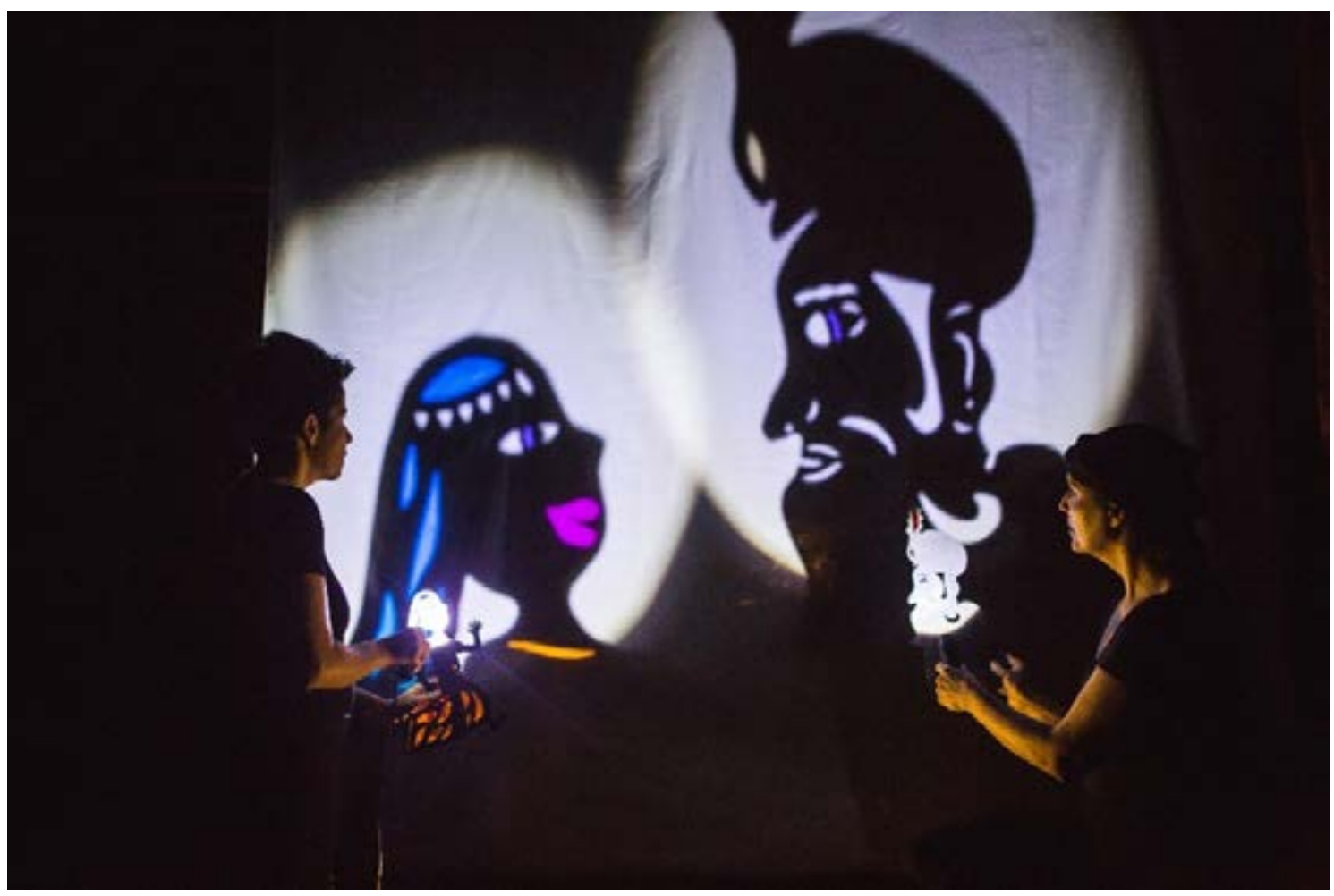

Foto 04 - Atrizes-sombristas aparentes, visível ao público, à frente da tela e fora da direção dos feixes de luz no espetáculo Um Encanto em Nagalândia (2015),

entre Aberta Cia Teatral, Florianópolis - Direção: Fabiana Lazzari e Tuany Fagundes Foto: Daniel Queiroz. 


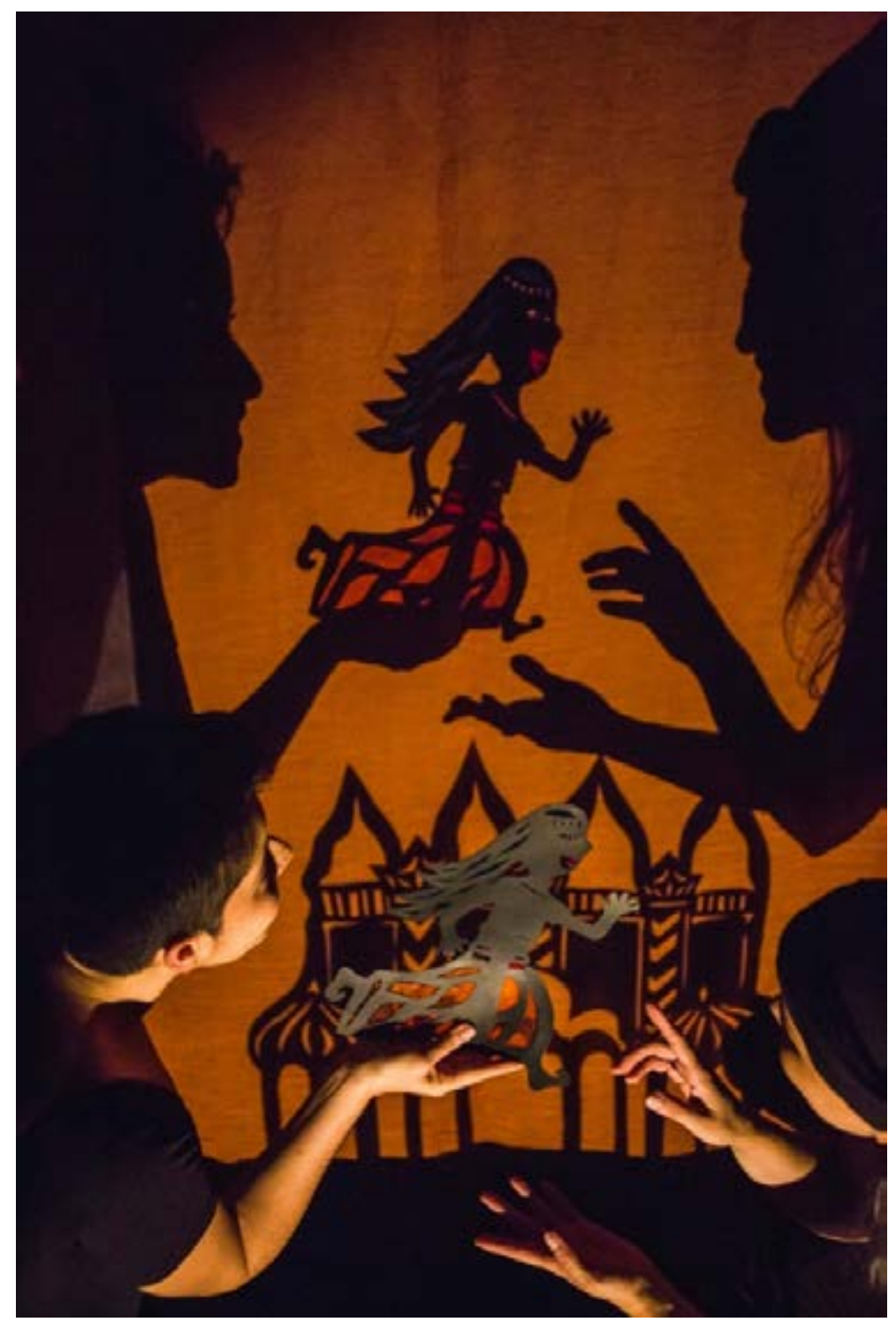

Foto 05 - Atrizes-sombristas aparentes, visível ao público, à frente da tela e dentro da direção dos

feixes de luz atuando com suas sombras e a sombra da silhueta-figura no espetáculo Um Encanto em Nagalândia (2015), entre Aberta Cia Teatral, Florianópolis - Direção: Fabiana Lazzari e Tuany Fagundes - Foto: Daniel Queiroz

É muito importante que a atrizsombrista execute as ações com fluência cognitiva e para isso é fundamental praticar, ensaiar, treinar. Para tal fluência, a atriz deve ter determinadas competências ${ }^{9}$.

Saliento que a ação do fazer não se dissocia do "se perceber fazendo"; por isso, a experiência, a percepção do ambiente que estamos inseridos na cena e a propriocepção são fundamentais para o teatro de sombras. Dentre as várias competências, as habilidades psicomotoras e cognitivas têm um papel fundamental para a atriz no teatro de sombras. Essas habilidades podem ser entendidas no âmbito da aprendizagem motora e da psicomotricidade.

Diversas competências da atriz no teatro de sombras estão relacionadas com a habilidade motora. Destaco que falarei de habilidade motora e não capacidade motora. Capacidade refere-se às qualidades físicas de uma pessoa, um potencial, definido

\footnotetext{
${ }^{9}$ O sociólogo Philippe Perrenoud, em entrevista para Paola Gentille e Roberta Bencini, conceitua a competência como "a faculdade de mobilizar um conjunto de recursos cognitivos (saberes, capacidades, informações, entre outros) para solucionar com pertinência e eficácia uma série de situações". Sendo assim, desenvolvem-se competências de acordo com o mundo de cada um. In Nova Escola (Brasil), setembro de 2000, p. 19-31.
} 
geneticamente, que pode ser atingido ou não. Enquanto habilidade se refere a uma tarefa com uma finalidade específica a ser atingida. Todos nascemos com determinada força, ou resistência, mas precisamos aprender a dançar, jogar basquete, tocar piano. Para a aprendizagem de qualquer habilidade motora é necessária uma seleção de informações que podem estar contidas no meio ambiente e/ou fornecidas por um professor ou técnico especialista no assunto, no caso do teatro, por um (a) professor(a), preparador(a) de atriz ou diretor(a).

No teatro de sombras, a atriz precisa aprender a trabalhar com diversos elementos que exigem habilidades motoras adequadas a eles e que podem ser adquiridas por meio de ensaios/treinamentos/práxis. Utilizo aqui a síntese das definições de aprendizagem motora existentes na literatura, como sugerida por João Augusto de Camargo Barros: "a aprendizagem motora se refere a mudanças internas na capacidade de executar habilidades motoras, sendo tais mudanças no sentido das execuções cada vez mais eficientes, relativamente permanentes e frutos de prática e experiência" $(2006$, p. 1).

No âmbito da aprendizagem motora, o conceito de habilidade vem definido por Magill:

É uma palavra comumente usada, que designa uma tarefa com uma finalidade específica a ser atingida. Por exemplo, $[. .$.$] tocar piano inclui uma habilidade que$ exige prática. [...] e inclui uma habilidade motora, porque é de fato uma habilidade que exige movimentos voluntários do corpo e/ou dos membros para atingir o objetivo. Analisando sob esse ângulo, a habilidade de tocar piano envolve as atividades de pressionar as teclas corretas na sequência certa e no tempo correto e exige movimentos de mãos e dedos para atingir o objetivo. (Magill, 2000, p. 6)

No teatro de sombras a atriz deve ter a habilidade de manipulação das silhuetas colocando-as no lugar certo para determinada projeção e movimentando-as no tempo correto e de acordo com as características da personagem; ou ainda, ter a habilidade de manipulação da fonte de luz dimmerizada para projetar sombras numa superfície qualquer tendo o controle de acionar o dimmer no tempo certo e ainda movimentar as mãos e braços num determinado ritmo (para os lados, para a frente e para trás) para atingir um objetivo.

A aprendizagem de uma habilidade passa por três estágios, segundo Fitts e Posner (1967): cognitivo, associativo e autônomo.

O estágio cognitivo (inicial) é a fase de identificação e desenvolvimento dos componentes da habilidade, isto é, envolve uma formação da imagem mental da habilidade. É o estágio onde haverá uma quantidade elevada de erros no desempenho e, portanto, um desempenho altamente inconsistente. O indivíduo é capaz de perceber o erro, mas não é capaz de solucionar o problema. O esforço cognitivo é muito grande tentando executar o que lhe pedem, exige um nível de atenção alto para a execução de várias tarefas. No teatro de sombras, esse esforço se torna nítido quando a atriz demonstra a dificuldade de segurar a fonte de luz, manipulá-la para projetar a sombra de uma silhueta e ainda olhar e atuar com a imagem da sombra projetada. Geralmente nas primeiras vivências a atriz não consegue fazer as três coisas ao mesmo tempo, ou olha para a manipulação da fonte de luz e não vê como a sombra está sendo projetada ou olha para a imagem da sombra e erra o caminho de manipulação da fonte de luz. 
O estágio associativo (intermediário) é a fase que envolve a prática da habilidade e o uso do feedback para aperfeiçoar a habilidade. É o estágio de refinamento, o indivíduo detecta alguns de seus erros no desempenho e, portanto, os erros são menos frequentes e a variação de desempenho também começa a decrescer.

O estágio autônomo (final) é a fase em que se desenvolve a habilidade para que se torne automática, dando autonomia para outras ações. Neste nível, não é preciso pensar conscientemente no que se está fazendo enquanto se desempenha a habilidade, é possível desempenhar duas tarefas ao mesmo tempo, se detectam os próprios erros e se realizam ajustes para corrigi-los.

É importante frisar que o processo de aprendizagem motora é contínuo, fato este que muitas vezes é negligenciado pelos autores que falam sobre ele. $O$ processo culmina na automatização, mas ele tem uma continuidade.

A atriz no teatro de sombras irá atingir o estágio autônomo com a praxis, isto é, quanto mais ensaios, mais adquirirá habilidades para o trabalho. E estes ensaios devem ser direcionados para as tarefas ou objetivos que se têm que cumprir, como: saber movimentar adequadamente a silhueta/figura/boneco/objeto ou o seu próprio corpo para projetar a sombra, entendendo que quando ela se afasta da fonte de luz e se aproxima da superfície de projeção, a sombra da silhueta ou do seu corpo diminui; e quando ela se aproxima da fonte de luz e se afasta da superfície de projeção, a sombra aumenta. Essa habilidade tornando-se automática proporcionará uma maior capacidade de criação, possibilitando que a atriz tenha maior clareza do todo e adquira autonomia para criar, assim como proporcionará que a atrizsombrista consiga trabalhar numa segunda tarefa que é também manipular a fonte de luz em suas mãos. Com a prática, o potencial de seleção e permanência de informações relevantes à atividade que estamos realizando é aperfeiçoado.

As habilidades motoras são importantes no teatro de sombras e podem ser treinadas ensaiando e vivenciando cada possibilidade necessária de acordo com o grau de dificuldade, trabalhando-se em estágios, por exemplo, primeiramente utilizando uma fonte de luz fixa e a silhueta/figura/boneco/objeto móvel, posteriormente uma fonte de luz móvel e a silhueta/figura/boneco/objeto fixa e, por fim, fonte de luz móvel e objeto/silhueta/boneco também móvel.

Com a experiência que a atrizsombrista adquire, o corpo padroniza os movimentos dos membros (inferiores e superiores) relativamente aos padrões dos eventos e dos objetos do ambiente, isto é, adquire uma coordenação. De acordo com Magill (2000, p. 39) quem controla o movimento coordenado é o nosso sistema nervoso. E a maioria das teorias que tentam explicar esse controle do movimento incorporam dois sistemas básicos: sistemas de controle de circuito aberto e o sistema de controle de circuito fechado. Como funcionam? Ambos têm um centro de controle, comandos de movimento provenientes desse centro de controle e executores do movimento. Porém, a diferença entre os dois é que um sistema de controle fechado envolve um feedback, enquanto que um sistema de controle aberto não. E qual é a importância do feedback?

No movimento humano, o feedback é a informação aferente enviada pelos vários receptores sensoriais para o centro de controle. A finalidade desse feedback é de manter o centro de controle constantemente atualizado sobre a correção com que o movimento está sendo realizado. (Magill, 2000, 41) 
O movimento humano é complexo e as fontes para termos um feedback podem ser tanto dos "executores", que permitem o movimento do corpo e dos membros, como pode provir dos receptores auditivos, visuais, táteis e proprioceptores (Magill, 2000, p. 41). Sendo assim, a atrizsombrista necessita também das habilidades psicomotoras como a velocidade de reação, a velocidade de deslocamento, a coordenação psicomotora, a percepção espaço-temporal e o ritmo. No teatro de sombras, a atriz utiliza o feedback na maioria das ações pois está trabalhando com muitos elementos ao mesmo tempo e geralmente no escuro ou em penumbra.

As habilidades psicomotoras são tão importantes quanto as habilidades motoras simples, para o desempenho da atrizsombrista em cena. As habilidades motoras simples são: força, velocidade, agilidade, flexibilidade, equilíbrio e resistência muscular, isto é, são as habilidades necessárias para se ter aptidão física para uma vida saudável. $\mathrm{E}$ as principais habilidades psicomotoras para o teatro de sombras são: esquema corporal (a habilidade que implica o conhecimento do próprio corpo, de suas partes, dos movimentos, dos gestos, das posturas e das atitudes), a velocidade de reação (capacidade do indivíduo de responder a um estímulo), velocidade de ação (diz respeito à orientação do emprego da velocidade), percepção espaço-temporal (requer um sistema de organização do movimento dentro de coordenadas vertical e horizontal, não só em relação ao próprio corpo, mas também em relação ao espaço e posição de objetos) e ritmo (do grego Rhytmus, significa "aquilo que flui, aquilo que se move", abrange o espaço e o tempo, reestrutura a ação e organiza o movimento e intensidade dentro de um tempo).

Dentre os processos cognitivos responsáveis por interpretarmos e apreendermos ou aprimorarmos as habilidades está a percepção, que engloba muitos fenômenos psicológicos e considero um processo com alta complexidade, principalmente para o trabalho no teatro de sombras, onde a atenção deve ser multifocal. O processo perceptivo é composto por várias fases, que começam com o estímulo ambiental e terminam com a percepção, o reconhecimento e a ação. Todo processo é tão dinâmico que não é possível afirmar se existe um início e um fim.

A percepção permite interpretar nossos entornos com os estímulos que recebemos por meio de nossos órgãos sensoriais: "é o conjunto de processos pelos quais reconhecemos, organizamos e entendemos as sensações que recebemos dos estímulos ambientais" (Sternberg, 2008, p. 115). É possível treinar e melhorar a percepção com uma estimulação cognitiva. A percepção é um processo ativo que requer que processemos informações com processamentos "ascendentes" e "descendentes", indicando que não somos dirigidos apenas pelos estímulos que recebemos (passivos, processamento ascendente), mas que esperamos e antecipamos determinados estímulos que controlam a percepção (ativos, processamentos descendentes).

Sistematicamente, a percepção pode ser dividida em cinco sentidos: o visual ou percepção visual ${ }^{10}$; auditiva ou percepção auditiva; tato, a percepção tátil, somatossensitiva ou percepção háptica; olfato ou percepção olfativa; e gosto ou percepção gustativa. Mas, existem também outros tipos de percepção: espacial, percepção do

\footnotetext{
10 Já abordada no Subcapítulo 1.9 - Imagem, Sensação e Percepção, da Minha Dissertação Alumbramentos de um corpo em sombras: 0 ator da Cia Teatro Lumbra de Animação, 2011, p. 72-81.
} 
formato, percepção vestibular, termocepção ou percepção térmica, nocipercepção ou percepção da dor, percepção de coceira, propriocepção, percepção interoceptiva, percepção cinestésica, percepção quimiossensorial, e magnetorecepção ou magnetocepção.

Dentre as principais habilidades que são adquiridas e/ou aprimoradas para se estar em corpo-sombra no teatro de sombras contemporâneo estão: a percepção visual, a percepção auditiva, a percepção háptica, a percepção do espaço, a percepção do formato, a percepção vestibular, a percepção térmica, a propriocepção, a percepção de tempo, a percepção cinestésica, a velocidade de ação e reação, a coordenação, o equilíbrio, a lateralidade, o grau de precisão de movimentos.

Quando a atrizsombrista pega a fonte de luz no chão conduzindo-a a uma altura e um posicionamento precisos perto da silhueta/figura/boneco/objeto e aciona o dimmer para iniciar um espetáculo de teatro de sombras, tanto o sistema proprioceptivo quanto o sistema senso-visual entram em funcionamento enquanto ela executa a ação. A propriocepção ajuda-a a pegar a fonte de luz no escuro e conduzi-la em direção à silhueta/figura/boneco/objeto. Sem essas informações sensoriais fornecidas pelos dois sistemas, provavelmente a atriz teria dificuldades para executar a tarefa:

A propriocepção envolve a identificação senso-receptora das características de movimento do corpo e dos membros. Os trajetos neurais aferentes enviam ao sistema nervoso central informação proprioceptiva sobre as características do movimento do corpo e dos membros, tais como orientação, localização espacial, velocidade e ativação muscular. (Magill, 2000, p. 57)

Nesta citação de Richard Magill, percebe-se a importância da propriocepção no trabalho da atriz no teatro de sombras, principalmente por estar no escuro e precisar controlar diversos elementos em cena.

Nicolas Gousseff discorre sobre a propriocepção no teatro de animação:

[do latim proprius, que significa "próprio", e da palavra "percepção"] designa o conjunto de receptores, vias e centros nervosos implicados na somastesia [sensibilidade profunda], que é a percepção de si mesmo, consciente ou não, ou seja, da posição dos diferentes membros e do seu tônus, em relação à situação do corpo relativamente à intensidade da atração terrestre. A propriocepção poderia ser considerada tanto o sexto quanto o primeiro dos nossos sentidos. Carrega a essência daquilo que os gregos designam por soma: não o corpo, mas o que o corpo remete ao ser na sua consciência de ser. O nosso corpo contém uma extraordinária paleta de atitudes (por estar permanentemente em situação). Cada uma delas é conhecida ao mesmo tempo numa forte impressão íntima quanto a sua sensação física e quanto à emoção por ela gerada. É mediante esse repertório que podemos reconhecer e compreender "o outro", no que transparece a sua atitude. Não podemos manipular um boneco se não transpusermos o nosso conhecimento proprioceptivo, já que a atitude é vetor da identificação, tanto do ator em relação a sua personagem quanto do espectador em relação a esta. (Gousseff, 2015, p. 106).

$\mathrm{Na}$ atualidade, a palavra soma foi reinventada por Thomas Hanna, filósofo, professor do Método Feldenkrais e editor da revista Somatics ${ }^{11}$, que distingue os

11 In: https://somatics.org/library/htl-wis1 
conceitos de corpo e soma: soma é o corpo subjetivo, ou seja, o corpo percebido do ponto de vista do indivíduo, em primeira pessoa. Quando um ser humano é observado de fora, por exemplo, do ponto de vista de uma terceira pessoa, quem é percebido é o corpo e não o soma do ser humano:

[...] o corpo como percebido de dentro pela percepção de primeira pessoa. Quando um ser humano é observado de fora - ou seja, de um ponto de vista de terceira pessoa - o fenômeno de um corpo humano é percebido. Mas, quando este mesmo ser humano é observado a partir do ponto de vista de primeira pessoa de seus próprios sentidos proprioceptivos, um fenômeno categoricamente diferente é percebido: o soma humano ${ }^{12}$. (Hanna, 1986, tradução nossa).

O soma, segundo Hanna (1986), é categoricamente distinto de um corpo, não porque o sujeito seja diferente, mas porque o ponto de vista é diferente, é propriocepção imediata, um modo sensorial que fornece modos únicos, que apenas a própria pessoa pode perceber: "O indivíduo enquanto observador tem uma experiência imediata de seu próprio corpo que é inacessível a qualquer outro observador. [...] Enquanto que um corpo é um objeto - uma coisa - o soma é um processo de sentimentos e de sensações com um sentido de movimento que está constantemente fluindo do passado para o futuro" (Hanna, 2007).

No teatro de sombras, é fundamental a atriz ter o ponto de vista em primeira pessoa, observando o seu corpo como um soma, pois assim, ativa os centros proprioceptivos buscando as informações factuais imediatas, necessárias para a atuação, donde estão presentes as experiências passadas e as expectativas futuras.

Magill expõe uma sensibilidade da propriocepção importante e que auxilia a atrizsombrista antes de tomar resoluções em determinadas ações no escuro: "diz respeito à discriminação entre intensidades ou níveis de um estímulo ou sinal" (2000, p. 58). Segundo ele, "essa discriminação é útil quando, por exemplo, uma pessoa precisa detectar diferentes níveis de brilho luminoso antes de tomar a decisão sobre um movimento específico" (Magill, 2000, p. 58). No caso do teatro de sombras, a atriz necessita constantemente lidar com essa sensibilidade. No escuro, ela precisa, por exemplo, perceber a hora em que a outra atrizsombrista inicia a cena acionando o dimmer do dispositivo de luz, isto é, a acuidade visual dessa atriz é um feedback proprioceptivo para o seu movimento. A propriocepção e a visão são duas fontes importantes de feedback envolvidas no controle do movimento. Segundo Magill, cada sistema sensorial tem seu próprio grau individual de sensibilidade para detectar diferenças de intensidade de estímulos e "para medir a sensibilidade de um sistema perceptivo, da forma como é usado nos julgamentos discriminativos, determinamos uma diferença apenas perceptível que é a menor alteração na intensidade de um estímulo que pode ser detectada corretamente por uma pessoa" (2000, p. 58). No teatro de sombras, caso a atriz não tenha uma grande capacidade de percepção visual, a cena pode ser prejudicada. A atrizsombrista deve detectar aquele pequeno brilho luminoso antes de entrar na cena com o seu dispositivo de luz e sua silhueta. Essa

\footnotetext{
$12[\ldots\}$ The body as perceived from within by first-person perception. When a human being is observed from the outside -- ie, from a third-person viewpoint-the phenomenon of a human body is perceived. But, when this same human being is observed from the first-person viewpoint of his own proprioceptive senses, a categorically different phenomenon is perceived: the human soma". (T. Hanna. In: https://somatics.org/library/htl-wis1 - acessado em 14/09/2017)
} 
limitação perceptiva está relacionada ao feedback que ela precisa ter para entrar na cena. A percepção da intensidade da luz, mesmo baixa, é um eficaz feedback para ela.

De acordo com as pesquisas descritas por Magill, o feedback proprioceptivo fornece informações de precisão espacial importantes no decorrer de um movimento. Ele afirma que o sistema nervoso está continuamente realimentando o centro de controle do movimento com informações proprioceptivas, o que permite a atualização das posições dos membros e, consequentemente, que a pessoa faça os ajustes necessários à trajetória correta dos membros. Portanto, uma das funções importantes do feedback proprioceptivo é o grau de precisão nos movimentos, o que considero ser fundamental para a atriz no teatro de sombras.

Acredito, como atrizsombrista, que para adquirir esse grau de precisão no teatro de sombras deve-se seguir alguns princípios que são comuns entre os métodos da educação somática ${ }^{13}$, entre eles: a diminuição de ritmo, a respiração e a autopesquisa.

A diminuição do ritmo com a proposição de que o aluno faça os movimentos de forma mais lenta do que habitualmente a fim que possa perceber as estruturas musculoesqueléticas implicadas quando executa o movimento. É o primeiro passo de uma tomada de consciência de como se executar um movimento de maneira justa. No teatro de sombras, os movimentos lentos são necessários, tanto para a tomada de consciência relatada acima como para conseguir ver e olhar para a imagem da sombra projetada de forma mais precisa, que não escape nenhum movimento, pois o movimento da imagem da sombra geralmente é mais lépido que o movimento do corpo da atriz. Em minhas práticas com teatro de sombras principalmente a partir do processo de criação do espetáculo $B R U X-$, a palavra que mais me acompanha nos momentos de criação e ensaios é devagar. Palavra mestra utilizada pelo diretor Alexandre Fávero. Esta palavra vai além do significado "sem pressa" ou "lentamente", usamo-la no sentido de forma progressiva, aos poucos. Assim as imagens da sombra projetada interessantes para contar uma história, não se tornam fugazes.

A respiração como suporte do movimento: o ritmo respiratório não é ditado para a execução do movimento, cada participante usa seu próprio ritmo respiratório como suporte do movimento. A atrizsombrista concebe os ritmos respiratórios corporais de acordo com as necessidades. No teatro de sombras contemporâneo, esse ritmo irá interferir nos movimentos e nas ações desempenhadas na cena. Se o ritmo respiratório estiver acelerado, é provável que irá afetar a forma de atuação com a fonte de luz, por exemplo, que está sendo manipulada pela atriz. A respiração é um processo fisiológico que está diretamente relacionada com a precisão do movimento.

A autopesquisa do movimento: as comandas não dirigem o participante à mera execução de uma sequência de movimentos, nem a um aperfeiçoamento dessa sequência, trata-se de incitá-lo a explorar, através do movimento, conexões entre partes do corpo aparentemente desconexas. O treinamento como práxis, cada uma terá que experimentar e buscar caminhos para as descobertas de cada movimento com os fundamentos técnicos do teatro de sombras. O falar, dar comandas de como

\footnotetext{
13 "A Educação Somática é um campo teórico-prático composto de diferentes métodos cujo eixo de atuação é o movimento do corpo como via de transformação de desequilíbrios mecânico, fisiológico, neurológico, cognitivo e/ou afetivo de uma pessoa" (Bonsanello, 2011, p. 306). Algumas técnicas que fazem parte da educação somática são: Técnica de Alexander, Feldenkrais, Antiginástica, Eutonia, Ginástica Holística, Continuum, Body Mind Centering, Cadeias Musculares e Articulares G.D.S., Somaritmo e certas linhas do método Pilates.
} 
fazer pode não ser a forma com que a outra vai apreender os fundamentos. O tempo de apreensão e o ritmo são individuais.

No teatro de sombras é imprescindível que a atriz tenha a consciência de que a sombra é tridimensional e que quando está dentro do espaço-sombra, a sombra ali também estará. O corpo da atrizsombrista ou a silhueta/figura/boneco/objeto estará em afecção com a sombra, produzindo uma imagem no suporte de projeção e fruída na sua superfície. Para animar a sombra corporal e todas as suas variantes com as silhuetas/figuras/bonecos/objetos, requer-se uma atitude do uso do corpo, e todas as técnicas que são utilizadas se baseiam neste corpo e nas capacidades da atrizsombrista para ter a postura adequada perante cada possibilidade. A atuação acontece com o corpo todo, mesmo não estando o corpo inteiro no espaço-sombra. A atrizsombrista deverá estar sempre em corpo-sombra durante a atuação. E para estar neste estado de atenção reitero que é indispensável praticar, individualmente e em conjunto. Por meio do treinamento como práxis e treinamento como poiésis adquirirá habilidades e/ou fortalecerá as habilidades motoras e psicomotoras acima descritas. Praticar o corpo-sombra é uma excelente forma de conquistar novas valências e/ou fortalecer habilidades já existentes.

As formas de experimentar, entender as próprias capacidades ampliar as habilidades e se perceber nos processos de criação com os fundamentos e elementos do teatro de sombras são primordiais. O êxito para essas assimilações está na experiência. Mas não simplesmente a experiência vivida, e sim aquela experiência viva, impressa pelos acontecimentos, no "aqui e agora". Estar em corpo-sombra é um treinamento cinestésico e proprioceptivo para a atriz.

\section{Referências}

BARROS, João Augusto de Camargo. Estrutura de Prática e Processo adaptativo em aprendizagem motora: efeitos da especificidade da tarefa. 97 p. Dissertação. Mestrado em Educação Física. Escola de Educação Física e Esporte, USP: 2006.

BERNARD, Michel. O Corpo. São Paulo: Apicuri, 2001.

DAMÁSIO, Antônio R. O Erro de Descartes. São Paulo: Companhia das Letras, 1996.

Em busca de Spinoza. Neurobiología de la emotíon y los sentimentos. Barcelona: ediciones Destinos, 2003.

FERRACINI, Renato. Ensaios de Atuação. São Paulo: Perspectiva, FAPESP, 2013.

FITTS, Paul. M.; POSNER, Michael. I. Human Performance. Belmont, Brooks/Colemann, 1967.

GIL, José Nuno. Abrir o corpo. In: Corpo, Arte e Clínica, organizado por Tania MaraGalli Fonseca e Selda Engelman. Porto Alegre: Ed. UFRGS, 2004. 
Movimento Total: O corpo e a dança. 2 imp. São Paulo: Iluminuras, 2009.

GOUSSEFF, Nicolas. Aprender a aprender. In: Móin-Móin: Revista de Estudos sobre o Teatro de Formas Animadas. Jaraguá do Sul: SCAR/UDESC, ano 11, v. 14, 2015.

HANNA, Thomas. What is Somatics? In: Somatics. New York, vol.5, $\mathrm{n}^{\circ} 4,1986$. Disponível em: https://somatics.org/library/htl-wis1. Acessado em: 14/09/2017.

MAGILL, Richard. A. Aprendizagem Motora - Conceitos e Aplicações. São Paulo: Edgard Blucher, 5a ed., 2000.

MERLEAU-PONTY, Maurice. Fenomenologia da Percepção. São Paulo: Martins Fontes, 1999.

NUNES, Sandra Meyer. As Metáforas do Corpo em Cena. São Paulo: Annablume/ UDESC, 2009.

OLIVEIRA, Fabiana Lazzari. Da prática pedagógica a atuação no Teatro de Sombras: um caminho na busca do Corpo-Sombra. Tese. UDESC: Florianópolis, 2018.

STERNBERG, Roberto J. Psicologia Cognitiva. Porto Alegre: Artmed, 2008.

Recebido em: 21/08/2018

Aprovado em: 21/08/2018 